\title{
Case Report: Total Gastric Necrosis as a Presentation of Aluminum Phosphide Poisoning: A Case Report
}

\author{
Arash Mohammadi Tofigh ${ }^{1}$ (D), Javad Zebarjadi Bagherpour ${ }^{1 *}$ (D) Parham Nikraftar $^{1}$ (D)
}

1. Departement of General Surgery, Imam Hossein Medical Center, Shahid Beheshti University of Medical Science, Tehran, Iran.

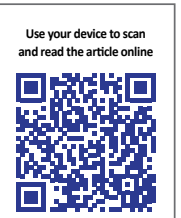

Citation: Mohammadi Tofigh A, Zebarjadi Bagherpour J, Nikraftar P. Total Gastric Necrosis as a Presentation of Aluminum Phosphide Poisoning: A Case Report. International Journal of Medical Toxicology and Forensic Medicine. 2020; 10(3):31244. https://doi.org/10.32598/ijmtfm.v10i3.31244

doi https://doi.org/10.32598/ijmtfm.v10i3.31244

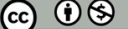

Article info:

Received: 06 July, 2020

First Revision: 10 July 2020

Accepted: 14 July 2020

Published: 21 Oct 2020

\section{Keywords:}

Aluminum Phosphide (AIP) poisoning, Complication, Peritonitis Introduction

\section{ABSTRACT}

Background: Rice pill poisoning is among the most frequent causes of death among poisoners. Despite advances in the treatment of this poisoning, its mortality rate remains high. The symptoms of Aluminum Phosphide (AlP) poisoning are varied and progressive. One of the essential foundations of diagnosis is based on the history of swallowing the pill by the patient or their companions.

Case Report: A 20-year-old woman with generalized abdominal pain and a diagnosis of peritonitis was operated. The operative finding was total gastric necrosis. After the operation, the patient's husband claimed that she had consumed some rice pills, intending to commit suicide. Despite all efforts, she remained in persistent septic shock and multi-organ failure and passed away after surgery.

Conclusion: Total gastric necrosis could be among the lethal complications of rice tablet (AlP) poisoning.

\section{Introduction}

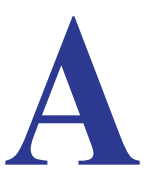

cute poisoning is a major global problem and among the major causes of morbidity and mortality [1]. The relevant mortality rate in the world varies from country to country. In developed countries, the poisoning-induced death rate is $1 \%-2 \%$ and this value is $1 \%-3 \%$ in Iran. The main use of these toxins as rodenticides worldwide is to store food and grains [2]. The pharmacology of phosphine toxin consists of the solid toxin in contact with gastric Hydrochloric Acid (HCL) or water that produces phosphine gas [3]. This toxin is recognized in Iran as the rice tablet and marketed in $3 \mathrm{~g}$ tablets under the name "Phostoxin"; it contains AlP (Phostoxin, Celphos, Quickphos, \& Phostek) [4].

It is a highly toxic product and its poisoning has a high mortality rate. As mentioned earlier, phosphine gas produced in contact with HCL in the stomach is rapidly absorbed in the gastrointestinal tract and generates toxic systemic effects on most organs, including the heart, lungs, and kidneys. Eventually, it causes severe acidosis, irreversible shock, and multiple organ failure [5]. In mild

* Corresponding Author:

Javad Zebarjadi Bagherpour, MD.

Address: Departement of General Surgery, Imam Hossein Medical Center, Shahid Beheshti University of Medical Science, Tehran, Iran

Tel: +98 (918) 2101497

E-mail:javad.zebarjady@yahoo.com 
poisoning, patients' symptoms include frequent nausea, vomiting, headache, diarrhea, and abdominal discomfort. These patients usually recover. [6]. However, in patients with moderate to severe intoxication, there are systemic, cardiovascular, and pulmonary shock and edema usually at the onset of intoxication. Subsequently, features of hepatic and renal failure and Disseminated Intravascular Coagulation (DIC) appear. In this study, we reported a patient presented with peritonitis due to total emphysematous gastric necrosis after the ingestion of rice tablets.

\section{Case Report}

A 20-year-old woman referred to the emergency department of Imam Hossein Medical Center in Tehran City, Iran with a sudden onset of generalized abdominal pain. She had nausea and coffee ground vomiting. She reported no medical or pharmacotherapy history. The patient's initial vital signs were unstable (Table 1). In physical examination, the abdomen was distended and she had generalized tenderness. A nasogastric tube was inserted and 550-milliliter coffee ground material was evacuated.

The laboratory data were as follows: White Blood Cells $(\mathrm{WBC})=12600 \mu \mathrm{L}$ with $58.9 \%$ neutrophils, hemoglobin=9.3 mg/dL, Na=142 $\mathrm{mEq} / \mathrm{L}, \mathrm{K}=4 \mathrm{mEq} / \mathrm{L}$, urea=21 $\mathrm{mg} / \mathrm{dL}$, creatinine $=1 \mathrm{mg} / \mathrm{dL}$. In terms of venous blood gas, $\mathrm{PH}=6.97, \mathrm{HCO} 3=15.1$, and $\mathrm{BE}=-17.3$. Liver function tests were normal. In addition, amylase $=\uparrow 238 \mathrm{U} / \mathrm{L}$, lipase $=\uparrow 69 \mathrm{U} / \mathrm{L}, \mathrm{CPK}=\uparrow \uparrow 2201 \mathrm{IU} / \mathrm{L}, \mathrm{CK}-\mathrm{MB}=\uparrow \uparrow 346$ $\mathrm{ng} / \mathrm{mL}$, and $\mathrm{LDH}=\uparrow 470 \mathrm{U} / \mathrm{L}$.

The patient was resuscitated and hydrated; after hydration in reevaluation, acidosis was better with $\mathrm{PH}=7.12$, and BE equaled approximately -12.2 . Abdominal X-Ray data suggested severe dilation of the stomach (Figure 1). The patient was transferred to the operation room with the diagnosis of peritonitis and laparotomy was performed. The operative finding was total gastric necrosis from the cardia to pylorus without perforation. In exploration, other organs were intact. Total gastrectomy and Roux-en-Y esophagojejunostomy were conducted.
The interpretation of $\mathrm{VBG}$ was as follows: $\mathrm{PH}=7.15$, $\mathrm{HCO} 3=16.1$, and $\mathrm{BE}=-14$.

After the operation, the patient's husband claimed that she had consumed some rice pills, intending to commit suicide. The patient was transferred to the Intensive Care Unit (ICU). In post-operation laboratory data, acidosis was aggravated with $\mathrm{PH}=6.82$ and $\mathrm{BE}=-19.4$. Furthermore, the patient developed multiple organ failure and irreversible shock. She was unfortunately expired 6 hours after the surgery. The pathology has reported emphysematous gastritis with mucosal necrosis with marked fullthickness congestion and hemorrhage (Figure 2).

\section{Discussion}

Pesticide poisoning is responsible for approximately 300000 deaths worldwide per year [7]. Organophosphates and phosphides, AlP, in particular, are the most prevalent pesticide agents. AlP is easily accessible and known as a suicide poison without an effective antidote [5]. Phosphine gas release is its toxicity mechanism that results from tablets reaching gastric HCL [1]. This gas provides a highly toxic effect on cellular function by creating a hypoxic condition, i.e., confirmed in histopathologic studies [8]. The cellular mechanism of toxicity is the effect on the cellular respiration system. It includes the inhibition of cytochrome $\mathrm{C}$ oxidase and mitochondrial function that form hydroxyl radicals [9]. In some studies, lipid peroxidation is also suggested for cellular injury [10].

Biochemical analysis in patients with AlP poisoning revealed increased superoxide dismutase activity and decreased catalase levels [11]. Glutathione is a catalyst for free radicals produced in the cell, i.e., a protective mechanism. In patients with ALP poisoning, glutathione levels are reduced, indicating cell damage in this poisoning [10]. Therefore, in the organs, such as stomach, vascular damage and the accumulation of gas in the cell cause damage and necrosis of stomach. The symptoms of this poisoning are due to its effects on various body organs, including the gastrointestinal tract, heart, kidneys, and lungs. Besides, they include nausea, vomiting, abdominal pain, palpita-

Table 1. Vital signs of the presented patient

\begin{tabular}{cccccc}
\hline Time of Vital Signs & PR/min & RR/min & Temp/Celsius & O $_{\mathbf{2}}$ Saturation & BP/mm \\
\hline Initial & 100 & 30 & 37 & $91 \%$ & $90 / 60$ \\
Post-resuscitation & 110 & 26 & 37.1 & $93 \%$ & $89 \%$ \\
Post-operation & 130 & 35 & 38.3 & $70 / 60$ \\
\hline
\end{tabular}



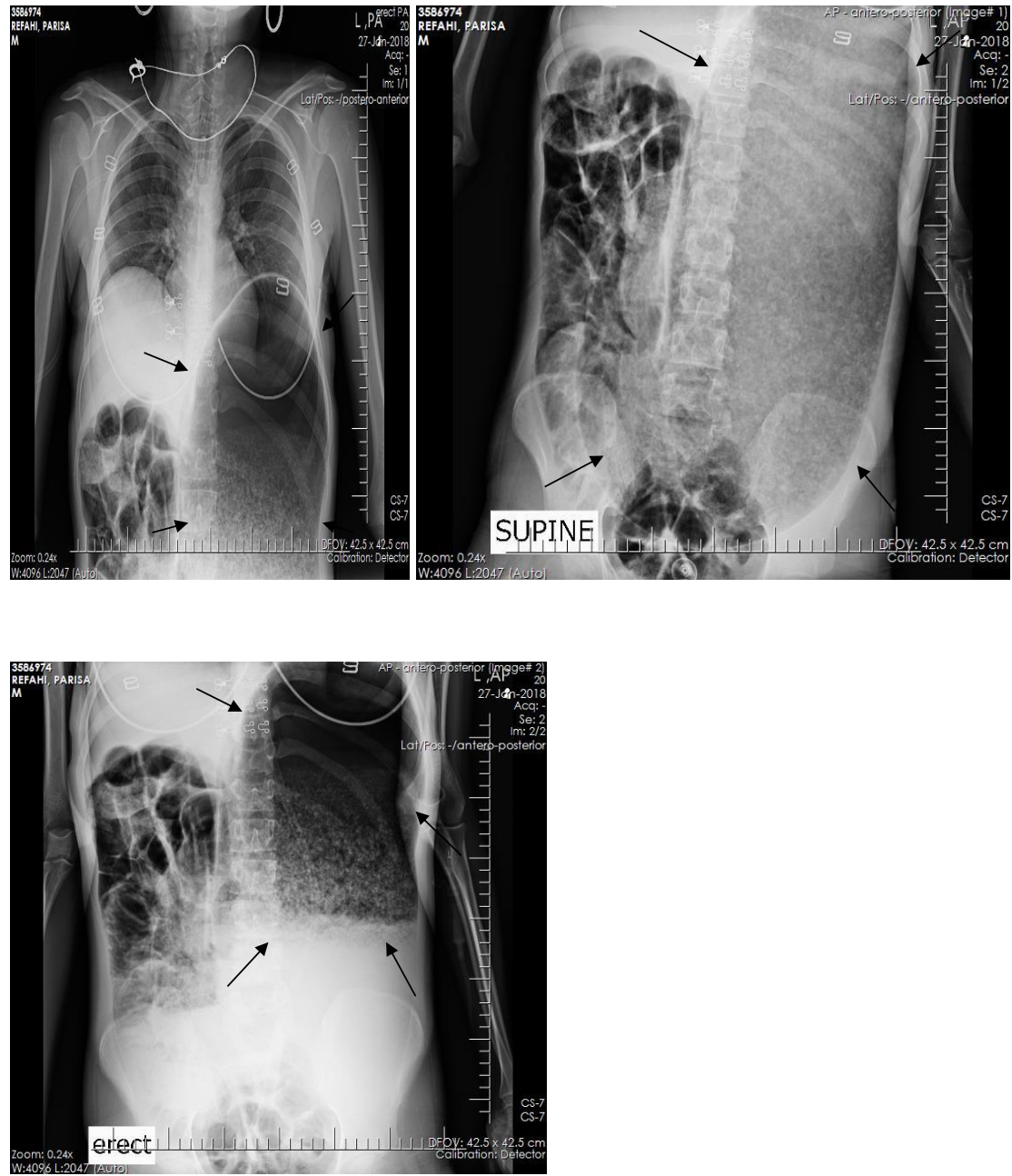

Figure 1. Sever gastric dilatation (arrows show the border of the stomach)

International Journal of

Medical Toxicology \& forensic Medicin

tion, restlessness, cardiac arrhythmias refractory shock, cyanosis, pulmonary edema, and sensory alterations [12].

The mortality rate of this poisoning ranges from $30 \%$ to $100 \%$, especially in doses $>1.5 \mathrm{~g}$ [4]. The lethal dose of ALP in adults is $150-500 \mathrm{mg}$; however, the reports of some cases indicated that patients survived even at doses of $9 \mathrm{~g}$ [13]. The diagnosis of AlP poisoning usually depends on clinical suspicion or history (self-report or by attendants) [14]. In our patient's history, the patient and
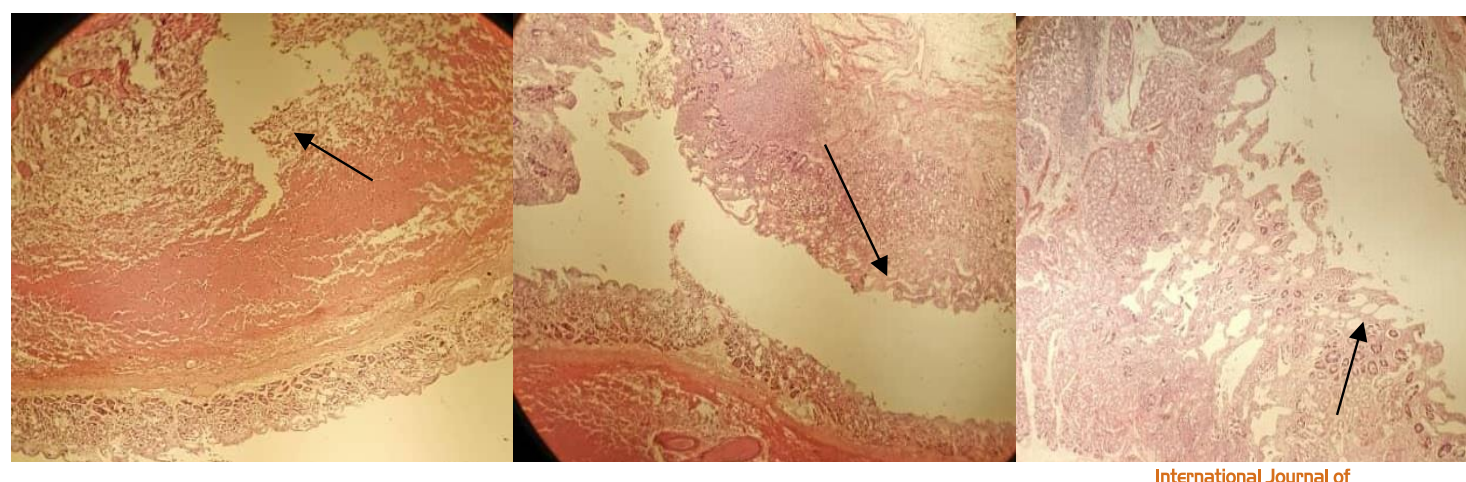

International Journal of
Medical Toxicology \& forensic Medicin

Figure 2. Pathologic findings indicating the emphysematous necrosis of the stomach (arrows show emphysema \& necrosis in the gastric wall) 
her companions denied the use of any drugs or other substances. Furthermore, after proper hydration, the patient underwent surgery with the diagnosis of peritonitis. After the surgery, the rice pill ingestion was approved by one of the patient's companions. Microscopic findings on rice pill poisoning vary from organ to organ. Sinha et al. reported degeneration, central venous congestion, bile stasis, hemorrhage, centrilobular necrosis, Kupffer cell hyperplasia, and sinusoidal dilation in the liver of these patients [15].

In the lung, microscopic findings were dilated capillaries, hemorrhage, alveolar thickening, edema, and collapsed alveoli. Degeneration, tubular dilation, infiltration, and cloudy swelling included the kidney analysis findings [16]. In our patient, the pathological finding was indicative of emphysematous gangrene in the stomach. Conventionally, the treatment of ALP poisoning includes gastric lavage with potassium permanganate and sometimes with sodium bicarbonate, the administration of charcoal, and palliative care [17]. Some studies have also described specific treatments that include early intravenous administration of sodium bicarbonate for acidosis, fluid, and vasopressor for cardiogenic shock, and an intra-aortic balloon pump or digoxin for refractory cardiogenic shock. In our case, the patient's hemodynamic condition changed rapidly after surgery, leading to severe acidosis, multiple organ damage, and irreversible shock. She failed to respond to other resuscitations and the patient was finally expired.

\section{Conclusion}

One of the lethal complications of rice tablet (AlP) poisoning could be total gastric necrosis.

\section{Ethical Considerations}

\section{Compliance with ethical guidelines}

This article does not contain any interventions on human or animal by any of the authors. In addition, information about the human case study group is anonymous in this study.

\section{Funding}

This research did not receive any grant from funding agencies in the public, commercial, or non-profit sectors.

\section{Author's contributions}

All authors contributed in preparing this article.

\section{Conflict of interest}

The authors declared no conflicts of interest.

\section{Acknowledgements}

The authors would like to thank to the supporting staff who contributed to this study.

\section{References}

[1] Bumbrah GS, Krishan K, Kanchan T, Sharma M, Sodhi GS Phosphide poisoning: A review of literature. Forensic Sci Int. 2012; 214(1-3):1-6. [DOI:10.1016/j.forsciint.2011.06.018] [PMID]

[2] Nosrati A, Karami M, Esmaeilnia M. Aluminum phosphide poisoning: A case series in north Iran. Asia Pac J Med Toxicol. 2013; 2(3):111-3. [DOI:10.22038/APJMT.2013.1674]

[3] Shields LBE, Hunsaker DM, Hunsaker JC, Ward MK. Toxicologic findings in suicide: A 10-year retrospective review of Kentucky medical examiner cases. Am J Forensic Med Pathol. 2006; 27(2):106-12. [DOI:10.1097/01.paf.0000220913.19508.99] [PMID]

[4] Mathai A, Bhanu MS. Acute aluminium phosphide poisoning: Can we predict mortality? Indian J Anaesth. 2010 54(4):302-7. [DOI:10.4103/0019-5049.68372] [PMID] [PMCID]

[5] Anand R, Kumari P, Kaushal A, Bal A, Wani WY, Sunkaria $\mathrm{A}$, et al. Effect of acute aluminum phosphide exposure on rats: A biochemical and histological correlation. oxicol Lett. 2012; 215(1):62-9. [DOI:10.1016/j.toxlet.2012.09.020] [PMID]

[6] Mehrpour O, Alfred S, Shadnia S, Keyler DE, Soltaninejad K, Chalaki N, et al. Hyperglycemia in acute aluminum phosphide poisoning as a potential prognostic factor. Hum Exp Toxicol. 2008; 27(7):591-5. [DOI:10.1177/0960327108096382] [PMID]

[7] Anand R, Binukumar BK, Gill KD. Aluminum phosphide poisoning: An unsolved riddle. J Appl Toxicol. 2011 31(6):499-505. [DOI:10.1002/jat.1692] [PMID]

[8] Alinejad S, Zamani N, Abdollahi M, Mehrpour O. A narrative review of acute adult poisoning in Iran. Iran J Med Sci. 2017; 42(4):327-46. [PMID] [PMCID]

[9] Rahbar Taromsari M, Teymourpour P, Jahanbakhsh R. [Survey the histopathological findings in autopsy of poisoned patients with rice tablet (Aluminium Phosphide) (Persian)] J Guilan Univ Med Sci. 2011; 19(76):56-63. http://journal gums.ac.ir/article-1-171-fa.html

[10] Kumar Pathak M, Rohini. Histopathological study of Liver in case of Aluminium Phosphide poisoning by SEM. IOSR J Environ Sci, Toxicol Food Tech. 2019; 13(11):39-45. https:// www.semanticscholar.org/paper/Histopathological-studyof-Liver-in-case-of-by-SEM-Pathak-Rohini/36f4f659d504881 b13323ff9d5e93c934649712c

[11] Faridaalaee G, Rahmani SH, Ahmadi S, Mahboubi A. An interesting case of aluminum phosphide poisoning. J Emerg Pract Trauma. 2016; 2(1):29-30. [DOI:10.15171/jept.2015.07] 
[12] Gupta S, Ahlawat SK. Aluminum phosphide poisoning-a review. J Toxicol Clin Toxicol. 1995; 33(1):19-24. [DOI:10.3109/15563659509020211] [PMID]

[13] Mehrpour O, Jafarzadeh M, Abdollahi M. A systematic review of aluminium phosphide poisoning. Arh Hig Rada Toksikol. 2012; 63(1):61-73. [DOI:10.2478/10004-1254-63-2012-2182] [PMID]

[14] Mirakbari SM. Hot charcoal vomitus in aluminum phosphide poisoning-A case report of internal thermal reaction in aluminum phosphide poisoning and review of literature. Indian J Anaest. 2015; 59(7):433-6. [DOI:10.4103/00195049.160952] [PMID] [PMCID]

[15] Sinha N. Aluminium phosphide poisoning.Indian J Med Spec. 2018; 9(3):167-70. [DOI:10.1016/j.injms.2018.06.006]

[16] Mehrpour O, Dolati M, Soltaninejad K, Shadnia S, Nazparvar B. Evaluation of histopathological changes in fatal aluminum phosphide poisoning. Indian J Forensic Med Toxicol. 2008; 2(2):34-6. https:// www.indmedica.com/journals.php?j ournalid=11\&issueid $=131 \&$ articleid $=1739 \&$ action=article

[17] VaghefiS, Emamhadi M. Aluminium phosphide poisoning: A case report. Int J Med Toxicol Forensic Med. 2014; 4(4 (Autumn)):149-53. [DOI:10.22037/ijmtfm.v4i4(Autumn).6041] 
This Page Intentionally Left Blank 